\title{
Preoperative anemia in patients undergoing coronary artery bypass grafting predicts acute kidney injury
}

\author{
Luca De Santo, $\mathrm{MD},{ }^{\mathrm{a}}$ Gianpaolo Romano, $\mathrm{MD},{ }^{\mathrm{b}}$ Alessandro Della Corte, $\mathrm{MD}, \mathrm{PhD},{ }^{\mathrm{c}}$ Vincenzo de Simone, $\mathrm{MD},{ }^{\mathrm{c}}$ \\ Francesco Grimaldi, MD, ${ }^{\mathrm{c}}$ Maurizio Cotrufo, $\mathrm{MD},{ }^{\mathrm{c}}$ and Marisa de Feo, $\mathrm{PhD}^{\mathrm{c}}$
}

\begin{abstract}
Objectives: Recent authoritative studies suggested that low preoperative hemoglobin concentration may affect cardiac surgery outcomes. This study aimed, primarily, to investigate whether preoperative anemia is an independent determinant of adverse events after coronary artery bypass grafting and, secondarily, to evaluate the potential dose responsiveness between anemia severity and primary end points.
\end{abstract}

\begin{abstract}
Methods: This single-center prospective study investigated 1214 consecutive patients undergoing coronary artery bypass grafting between January 2004 and June 2007, collecting 100 variables per patient. In 1047 patients (median age 64 years, $18.8 \%$ female, 38.9\% diabetic, 31.9\% urgent/emergency, 15.3\% with low preoperative left ventricular ejection fraction) who underwent on-pump procedures and received no preoperative transfusion, the prevalence of preoperative anemia (according to World Health Organization definition) and its unadjusted and adjusted relationships with in-hospital death, cardiac morbidity, and acute kidney injury (AKI-RIFLE [Risk, Injury, Failure, Loss, End-stage kidney disease] criteria) were obtained.
\end{abstract}

Results: The prevalence of preoperative anemia was $28 \%$. In-hospital death averaged $3.9 \%$, cardiac morbidity $7.3 \%$, and acute kidney injury $4 \%$. Unadjusted odds ratios (Ors) for in-hospital death, cardiac morbidity, and acute kidney injury were 3.8 (95\% confidence interval [CI] 2.0-7.3), 1.7 (95\% CI 1.1-2.8), and 4.0 (95\% CI 2.1-7.6), respectively. Adjusting for anemia in confounders proved an independent predictor of acute kidney injury (OR 2.06; 95\% CI 1.14-3.70), whereas the cardiac morbidity and in-hospital mortality were independently predicted by kidney function. No dose-response relationship emerged between anemia severity and acute kidney injury.

Conclusions: Preoperative anemia is independently associated with acute kidney injury after coronary artery bypass grafting. Further studies are warranted to determine whether preoperative low hemoglobin concentration is a marker of severity of illness or a modifiable risk factor.

Despite polarized positions on the benefits and risks of perioperative transfusions, uncertainty still exists over the impact of preoperative anemia in patients undergoing cardiac surgery. ${ }^{1,2}$ Indeed, this feature is increasingly encountered in the already complex comorbid profile of the relentlessly aging population referred for surgery. Data from recent authoritative studies ${ }^{3-6}$ have disclosed preoperative hemoglobin concentration as an independent risk factor for an unfavorable outcome. Acute renal failure (ARF) and neurologic injury, two of the most dreaded complications of cardiac surgical procedures, were found to be statistically linked to severe anemia. Furthermore, the causal relation of different degrees of anemia severity to suboptimal out-

From the Department of Cardiac Surgery, ${ }^{\mathrm{a}}$ University of Foggia, Foggia, Italy; and the

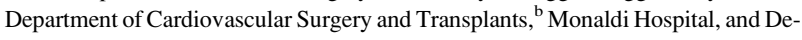
partment of Cardiothoracic Sciences, ${ }^{\mathrm{c}}$ Second University of Naples, Naples, Italy. Presented at the American Heart Association Scientific Sessions 2008 in New Orleans, La; Abstract Oral Sessions; Cardiac Surgery: Coronary Artery Disease; 18571.

Received for publication Jan 2, 2009; revisions received April 8, 2009; accepted for publication May 15, 2009; available ahead of print July 2, 2009.

Address for reprints: Luca De Santo, Viale Colli Aminei 491, 80131, Naples, Italy (E-mail: luca.desanto@ospedalemonaldi.it).

J Thorac Cardiovasc Surg 2009;138:965-70

$0022-5223 / \$ 36.00$

Copyright (c) 2009 by The American Association for Thoracic Surgery

doi:10.1016/j.jtcvs.2009.05.013 comes is still under investigation, largely jeopardizing the odds for the development and validation of preventive management algorithms.

As part of our hospital's ongoing continuous quality improvement program, we performed a prospective cohort study designed to survey blood transfusion practice and its effects on outcomes after cardiac surgical procedures. This database was later used to determine the prevalence and examine the implications of preoperative anemia in patients referred for coronary artery bypass grafting $(\mathrm{CABG})$ in a tertiary care, university-affiliated center.

\section{METHODS}

\section{Study Setting and Patient Sample}

The study was conducted at the Department of Cardiothoracic and Respiratory Sciences of the Second University of Naples located in an affiliated teaching hospital (V. Monaldi Hospital). At our institution, nearly 800 patients have cardiac surgery annually and are admitted to a dedicated 12-bed postoperative intensive care unit. Information from these patients is collected on a daily basis using standardized case report forms; 100 perioperative data points (including demographics, laboratory tests, nature of surgery, blood product transfusions, re-exploration, postoperative complications, and lengths of stay in the intensive care unit and hospital) are collected. Data are entered into a computerized database, which is programmed to accept only matching double-entry data falling within 


\section{Abbreviations and Acronyms \\ AKI = acute kidney injury \\ $\mathrm{ARF}=$ acute renal failure \\ $\mathrm{CABG}=$ coronary artery bypass grafting \\ $\mathrm{CKD}=$ chronic kidney disease \\ $\mathrm{CPB}=$ cardiopulmonary bypass \\ GFR $=$ glomerular filtration rate \\ RIFLE $=$ Risk, Injury, Failure, Loss, \\ End-stage kidney disease \\ WHO $=$ World Health Organization}

pre-specified ranges. All queries are resolved by referring to the patients' original records. Of 1214 consecutive patients undergoing CABG between January 2004 and June 2007, 1047 patients (median age 64 years, 18.8\% female, $38.9 \%$ diabetic, $31.9 \%$ urgent/emergency, $15.3 \%$ with low preoperative left ventricular ejection fraction) who underwent on-pump procedures, received no preoperative transfusion, and were not receiving renal replacement therapy constituted the study sample.

\section{Surgical and Clinical Care}

Details on surgical procedure and postoperative care have been reported extensively elsewhere. ${ }^{7,8}$ Aprotinin was never used for bleeding prevention because it is not authorized in our country; tranexamic acid was given preoperatively to patients on dual antiplatelet therapy. Heparinization was managed by both heparin blood level and activated coagulation time monitoring throughout the operation. An intraoperative autologous blood salvage method was used in every patient with preoperative anemia or dual antiplatelet therapy. A specific perioperative transfusion algorithm was applied: for example, the patients received two units of packed red cells before cardiopulmonary bypass $(\mathrm{CPB})$ whenever the preoperative hematocrit value was below $30 \%$, and they received two or more units of packed red cells during CPB in case of excessive hemodilution (hematocrit value below $22 \%$ ). After $\mathrm{CPB}$, the patients received packed red cells to maintain a hematocrit value higher than $25 \%$. This target value was raised to higher values according to the clinical condition, and namely to the hemodynamic status, the need for inotropic support, and the age of the patient. Fresh frozen plasma was not used before reaching the intensive care unit. Platelets were usually not transfused unless in patients reaching the operating room under full dose of ticlopidine or clopidogrel and demonstrating severe postoperative bleeding. Such protocol complies with current practice in other centers and recently published guidelines. ${ }^{9,10}$

\section{Study Design and Aims}

An observational cohort design was used segregating study patients according to the presence or absence of preoperative anemia. The prevalence of preoperative anemia and its relationships with in-hospital death, cardiac morbidity, and acute kidney injury (AKI) were obtained. Research protocol was approved by the local ethics and research committee, which waived the need for informed consent.

\section{Baseline Data and Clinical Outcomes}

All definitions were selected prospectively as part of the original study design. The preoperative hemoglobin level was prospectively defined as the lowest documented hemoglobin value among those measured at admission, during the preoperative period, or immediately before induction of anesthesia. Gender-based definition of anemia $(12.0 \mathrm{~g} / \mathrm{dL}$ in women and 13.0 $\mathrm{g} / \mathrm{dL}$ in men) complied with statements by the World Health Organization (WHO). ${ }^{11}$ The WHO grading scale for anemia severity was adopted. ${ }^{11}$ This scale categorizes anemia into five grades based on hemoglobin levels: grade 0 (>11.0 g/dL); grade 1 (mild, $10.0-9.5 \mathrm{~g} / \mathrm{dL}$ ); grade 2 (moderate, 9.4-8.0 g/dL); grade 3 (serious/severe, $7.9-6.5 \mathrm{~g} / \mathrm{dL}$ ); and grade 4 (lifethreatening, $<6.5 \mathrm{~g} / \mathrm{dL})$.

The change in kidney function was based on plasma creatinine concentration and defined as the difference between baseline concentration and the highest concentration during the stay in the intensive care unit. Preoperative glomerular filtration rate (GFR) and smallest GFR during intensive care unit stay were calculated with the Modification of Diet in Renal Disease equation: estimated GFR $=186 \times$ (plasma creatinine level $[\mathrm{in} \mathrm{mg} /$ $\mathrm{dL}]^{-1.154} \times(\text { age [in years] })^{-0.203}$. For women, the product of this equation was multiplied by a correction factor of $0.742 .{ }^{12}$ To classify preoperative kidney function, we adopted the National Kidney Foundation Classification staging system. ${ }^{13}$ The severity of chronic kidney disease (CKD) is described by six stages: the most severe three are defined by the Modification of Diet in Renal Disease -estimated GFR value, and the first three also depend on whether there is other evidence of kidney disease (eg, proteinuria).

Stage 0 . Normal kidney function: GFR above $90 \mathrm{~mL} \cdot \mathrm{min}^{-1} \cdot(1.73$ $\left.\mathrm{m}^{2}\right)^{-1}$ and no proteinuria

Stage 1. CKD1: GFR above $90 \mathrm{~mL} \cdot \mathrm{min}^{-1} \cdot\left(1.73 \mathrm{~m}^{2}\right)^{-1}$ with evidence of kidney damage

Stage 2. CKD2 (mild): GFR of 60 to $89 \mathrm{~mL} \cdot \mathrm{min}^{-1} \cdot\left(1.73 \mathrm{~m}^{2}\right)^{-1}$ with evidence of kidney damage

Stage 3. CKD3 (moderate): GFR of 30 to $59 \mathrm{~mL} \cdot \mathrm{min}^{-1} \cdot\left(1.73 \mathrm{~m}^{2}\right)^{-1}$

Stage 4. CKD4 (severe): GFR of 15 to $29 \mathrm{~mL} \cdot \mathrm{min}^{-1} \cdot\left(1.73 \mathrm{~m}^{2}\right)^{-1}$

Stage 5. CKD5 kidney failure (dialysis or kidney transplant needed): GFR less than $15 \mathrm{~mL} \cdot \mathrm{min}^{-1} \cdot\left(1.73 \mathrm{~m}^{2}\right)^{-1}$

For postoperative AKI, the classification by the Acute Dialysis Quality Initiative Workgroup was referred to. This classification has been named RIFLE according to the severity of renal impairment. ${ }^{14}$ The standard defines three grades of severity-risk (class R), injury (class I) and failure (class F) — and two outcome classes-loss of kidney function and end-stage kidney disease. This classification system includes separate criteria for creatinine and urine output. A patient can fulfill the criteria through changes in serum creatinine, GFR, or urine output: the criterion that leads to the worst possible classification should be used. Class $\mathrm{R}$ is considered if there is an increase of serum creatinine $\times 1.5$ or a GFR decrease greater than $25 \%$ or a urinary output less than $0.5 \mathrm{~mL} \cdot \mathrm{kg}^{-1} \cdot \mathrm{h}^{-1}$ for 6 hours; class I is considered if there is an increase of serum creatinine $\times 2$ or a GFR decrease greater than $50 \%$ or a urinary output less than $0.5 \mathrm{~mL} \cdot \mathrm{kg}^{-1} \cdot \mathrm{h}^{-1}$ for 12 hours; and class $\mathrm{F}$ is considered if there is an increase of serum creatinine $\times 3$ or a GFR decrease greater than $75 \%$; in patients with a serum creatinine greater than $4 \mathrm{mg} / \mathrm{dL}$, if there is an acute rise in serum creatinine of at least $0.5 \mathrm{mg} / \mathrm{dL}$ or a urinary output less than $0.3 \mathrm{~mL} \cdot \mathrm{kg}^{-1} \cdot \mathrm{h}^{-1}$ for 24 hours or anuria for 12 hours. The main parameters considered in this study for ARF definition were creatinine and GFR, due to the heterogeneity of volemia status and diuretic use in the study patients, affecting the relationship between renal status and urine output.

Cardiac morbidity was defined as the occurrence of myocardial infarction and/or heart failure. The diagnosis of myocardial infarction required the development of new Q waves, new persistent ST-segment or T-wave changes associated with an elevation of creatinine kinase MB isoenzyme values, or autopsy evidence of acute myocardial infarction. The diagnosis of heart failure required either the use of an intra-aortic balloon pump or ventricular assist device, the use of continuous inotropic support for at least 24 hours, or autopsy evidence of heart failure. Fatality (hospital mortality) was defined as death occurring after surgery and during the index hospitalization.

\section{Statistical Analysis}

Data are expressed as mean \pm SD for continuous variables and as percentages for categorical variables. Multivariable logistic regression modeling was carried out to assess the independent relationship between preoperative anemia and the adverse outcomes. Initially, bivariate analyses 
TABLE 1. Preoperative characteristics

\begin{tabular}{|c|c|c|c|c|}
\hline Baseline and surgical characteristics & $\begin{array}{l}\text { Study population } \\
\quad(\mathrm{n}=1047)\end{array}$ & $\begin{array}{l}\text { Anemia present } \\
\quad(\mathbf{n}=\mathbf{3 2 0})\end{array}$ & $\begin{array}{l}\text { Anemia absent } \\
\quad(\mathbf{n}=727)\end{array}$ & $P$ value \\
\hline Age (y) & $63.2 \pm 9.3$ & $66.9 \pm 8.9$ & $61.5 \pm 9.1$ & $<.0001$ \\
\hline Body surface area $\left(\mathrm{m}^{2}\right)$ & $1.84 \pm 0.16$ & $1.81 \pm 0.14$ & $1.85 \pm 0.16$ & $<.0001$ \\
\hline Female sex $(\%)$ & 18.8 & 25.3 & 16 & .001 \\
\hline Diabetes mellitus (type I or II) (\%) & 38.9 & 39.4 & 38.7 & .07 \\
\hline Hypertension $(\%)$ & 70.1 & 70.9 & 69.7 & .69 \\
\hline $\operatorname{COPD}(\%)$ & 13.7 & 13.5 & 13.1 & .08 \\
\hline Peripheral vascular disease $(\%)$ & 5.9 & 6.0 & 5.8 & .52 \\
\hline Cerebrovascular disease $(\%)$ & 6.9 & 7.1 & 6.6 & .41 \\
\hline Hypercholesterolemia (\%) & 41.4 & 41.8 & 41.2 & .67 \\
\hline Recent myocardial infarction (\%) & 29.9 & 35.6 & 29 & .04 \\
\hline Left ventricular ejection fraction $<35 \%(\%)$ & 15.3 & 20.3 & 13.1 & .004 \\
\hline Baseline eGFR $\left(\mathrm{mL} \cdot \min ^{-1} \cdot\left[1.73 \mathrm{~m}^{2}\right]^{-1}\right)$ & $64.2 \pm 31.6$ & $60.2 \pm 49.56$ & $66.2 \pm 18.7$ & $<.0001$ \\
\hline \multicolumn{5}{|l|}{ Preoperative medications $(\%)$} \\
\hline Heparin within $24 \mathrm{~h}$ of surgery (\%) & 7.4 & 10 & 6.2 & .019 \\
\hline Warfarin (within $5 \mathrm{~d}$ of surgery) & 0.7 & 1.3 & 0.4 & .2 \\
\hline Acetylsalicylic acid within $5 \mathrm{~d}$ of surgery $(\%)$ & 45.2 & 45.3 & 45.1 & 1 \\
\hline Clopidogrel within $5 \mathrm{~d}$ of surgery $(\%)$ & 14.2 & 15.4 & 13.7 & .5 \\
\hline Angiotensin-converting enzyme inhibitor $(\%)$ & 42.4 & 43.4 & 45.4 & .58 \\
\hline
\end{tabular}

$C O P D$, Chronic obstructive pulmonary disease; $e G F R$, estimated glomerular filtration rate.

(using the $\chi^{2}$ statistic for categorical variables and the $\mathrm{t}$ test or Wilcoxon rank sum test for continuous variables) were carried out to identify preoperative, intraoperative, and postoperative variables that were associated with preoperative anemia, as defined above, and the adverse outcomes. Variables that were not linearly related were mathematically transformed, categorized along appropriate cut points, or converted into multiple dichotomous variables. All clinically sensible variables with values of $P<.3$ in bivariate associations were entered into multivariable logistic regression models. Subsequent retention in these models was determined with backward stepwise selection, where $P<.1$ was the criterion for variable retention. Two of these variables deserve special consideration: red blood cell transfusions and preoperative anemia. Red blood cell transfusion is obviously a covariate of low hemoglobin concentration at any stage during patient care, and the preoperatively anemic patient in the present series had a 2 -fold likelihood to receive a transfusion in respect to the nonanemic counterpart. Many triggers different from preoperative anemia may develop during the process of care and determine transfusional need. A propensity score for the likelihood to receive red blood cell transfusion was calculated to balance the effect of preoperative anemia on the overall transfusional need throughout the process of care. ${ }^{15}$ Prognostic factors available in the database were entered into a bivariate analysis using as dependent variable a dummy dichotomous variable reflecting the prevalence of transfused patients. Propensity scoring was then derived by multivariable discriminant analysis by single step enter method. The $\mathrm{C}$ statistic for such propensity model was 0.81 . Propensity score was forced to enter in the analysis for study end points as a linear covariate (except for the cardiac morbidity model because of redundancy).
Preoperative anemia was entered into the analysis both as a dichotomous variable (absence or presence) and also as a multimodal categorical variable according to the prespecified anemia severity scoring. All statistical analyses were performed with SPSS 10.0 (SPSS Inc, Chicago, Ill).

\section{RESULTS}

\section{Study Population}

Prevalence of preoperative anemia was $28 \%$. Anemia severity according to WHO scaling system was: 0 (none) $71.9 \%, 1$ (mild) $20 \%, 2$ (moderate) $7.8 \%$, and 3 (severe) $0.3 \%$. Table 1 summarizes demographic characteristics along with medical history and preoperative medications. Anemic patients proved to have a significantly more complex comorbidity profile. Table 2 displays main surgical characteristics. Anemic patients had a significantly higher surgical priority status. No difference emerged as to other features of surgical procedure.

\section{Perioperative Hemoglobin Levels and Transfusion Practice}

Details on hemoglobin levels and transfusion requirements during the perioperative period are reported in Table 3. Nearly $45.9 \%$ of the study population received a transfusion

TABLE 2. Surgical characteristics

\begin{tabular}{|c|c|c|c|c|}
\hline Surgical characteristics & Study population $(n=1047)$ & Anemia present $(\mathbf{n}=\mathbf{3 2 0})$ & Anemia absent $(n=727)$ & $P$ value \\
\hline Emergent surgery $(\%)$ & 7.4 & 10 & 6.2 & .019 \\
\hline Urgent surgery $(\%)$ & 24.5 & 27.5 & 23.2 & .019 \\
\hline Redo surgery $(\%)$ & 1.0 & 1.3 & 0.8 & .5 \\
\hline Distal anastomosis, No. & $2.66 \pm 0.84$ & $2.67 \pm 0.83$ & $2.66 \pm 0.85$ & .78 \\
\hline CPB duration (min) & $83.9 \pm 33.2$ & $85.3 \pm 35.5$ & $83.2 \pm 32.2$ & .348 \\
\hline Aortic crossclamp duration (min) & $44.9 \pm 20.2$ & $45.2 \pm 20.4$ & $44.8 \pm 20.1$ & .799 \\
\hline Indexed CPB flow $\left(\mathrm{L} \cdot \mathrm{min}^{-1} \cdot \mathrm{m}^{-2}\right)$ & $2.37 \pm 0.2$ & $2.39 \pm 0.12$ & $2.36 \pm 0.23$ & .06 \\
\hline
\end{tabular}

$C P B$, Cardiopulmonary bypass. 
TABLE 3. Perioperative Hb/Hct and transfusions variables

\begin{tabular}{|c|c|c|c|c|}
\hline Perioperative $\mathrm{Hb} / \mathrm{Hct}$ and transfusion variables & Study population $(n=1047)$ & Anemia present $(n=320)$ & Anemia absent $(n=727)$ & $P$ value \\
\hline $\mathrm{Hb}$, preoperative $(\mathrm{g} / \mathrm{dL})$ & $13.42 \pm 1.69$ & $11.49 \pm 1.15$ & $14.27 \pm 1.08$ & $<.0001$ \\
\hline RBCs during CPB (mean $\pm \mathrm{SD}$ ) & $0.55 \pm 1.06$ & $1.25 \pm 1.41$ & $0.25 \pm 0.67$ & $<.0001$ \\
\hline Hct, lowest during CPB (\%) & $27.3 \pm 3.9$ & $25.4 \pm 3.2$ & $28.1 \pm 3.9$ & $<.0001$ \\
\hline $\mathrm{Do}_{2}$, lowest during $\mathrm{CPB}\left(\mathrm{mL} \cdot \min ^{-1} \cdot \mathrm{m}^{-2}\right)$ & $297.6 \pm 48.9$ & $279.8 \pm 38$ & $305.5 \pm 51.1$ & $<.0001$ \\
\hline $\mathrm{RBCs}$ in $\mathrm{OR}($ mean $\pm \mathrm{SD})$ & $0.8 \pm 1.54$ & $1.66 \pm 1.88$ & $0.43 \pm 1.04$ & $<.0001$ \\
\hline $\mathrm{Hb}$, ICU admission (g/dL) & $9.33 \pm 1.16$ & $8.8 \pm 0.9$ & $9.5 \pm 1.1$ & $<.0001$ \\
\hline Chest drains $(\mathrm{mL} / 24 \mathrm{~h})$ & $702.6 \pm 356.6$ & $702.6 \pm 356.6$ & $727.9 \pm 365.8$ & .3 \\
\hline Resternotomy for bleeding (\%) & 2.4 & 2.5 & 2.3 & .514 \\
\hline RBCs in ICU & $1.07 \pm 1.92$ & $1.50 \pm 2.27$ & $0.88 \pm 1.71$ & $<.0001$ \\
\hline Overall $\mathrm{RBC}$ transfusion (mean $\pm \mathrm{SD}$ ) & $2.05 \pm 2.89$ & $3.39 \pm 3.52$ & $1.46 \pm 2.34$ & $<.0001$ \\
\hline Overall PLT transfusion & $1.60 \pm 3.97$ & $1.95 \pm 5.11$ & $1.45 \pm 3.32$ & $<.0001$ \\
\hline Overall FFP transfusion & $1.54 \pm 3.22$ & $1.96 \pm 3.67$ & $1.36 \pm 2.98$ & .006 \\
\hline Transfused patients $(\%)$ & 45.9 & 71.6 & 34.7 & $<.0001$ \\
\hline
\end{tabular}

$\mathrm{Hb}$, Hemoglobin; $\mathrm{Hct}$, hematocrit; $R B C$, red blood cell; $C P B$, cardiopulmonary bypass; $S D$, standard deviation; $D o_{2}$, oxygen delivery; $O R$, operating room; $I C U$, intensive care unit; $P L T$, platelet; $F F P$, fresh frozen plasma.

during the hospitalization. Anemic patients received significantly more red blood cells, fresh frozen plasma, and platelet transfusions during each step of the process of care but never reached hemoglobin levels comparable with those registered in the nonanemic subset.

\section{Study End Points}

Anemic patients had significantly worse outcomes in terms of both primary end point and overall hospital morbidity as depicted in Table 4. National Kidney Foundation grading of preoperative estimated GFR was significantly higher in the anemic subgroup; both study samples had a significant worsening of renal function after the surgical procedure. Incidence of AKI according to RIFLE scoring was significantly higher in the anemic subgroup (Normal 59.4\%, Risk $31.2 \%$, Injury $7.5 \%$, and Failure $1.9 \%$ versus Normal $60 \%$, Risk $33.3 \%$, Injury $3.4 \%$, and Failure $0.3 \%$ (Figure 1). Hospital mortality rates in RIFLE classes for the anemic subset were as follows: Normal $2.6 \%$, Risk $7 \%$, Injury $37.5 \%$, and Failure $66.7 \%$. Fatality rate for the nonanemic counterpart were as follows: Normal $0.9 \%$, Risk $2.5 \%$, Injury $20 \%$, and Failure $50 \%$.

Multivariable logistic regression analysis for primary end points is reported in Table 5. Age, baseline kidney function (estimated GFR), RIFLE scoring, and propensity scoring for transfusion proved independent predictors of hospital mortality. Preoperative anemia emerged as an independent predictor of AKI along with insulin-dependent diabetes mellitus and propensity score for transfusion. No dose-response relationship between anemia severity and AKI emerged. Recent myocardial infarction, peak postoperative renal function (estimated GFR), need for transfusions, and CPB length independently predicted cardiac complications.

\section{DISCUSSION}

This prospective observational single-center study of an unselected consecutive series of on-pump CABG procedures found that preoperative anemia was a highly prevalent feature that independently predicted AKI. Prevalence of anemia and complexity of preoperative comorbid profile of the patient subset are homogeneous to that disclosed in available series of patients undergoing cardiac surgery. ${ }^{3-6}$ ARF after cardiac surgery, depending on the specific definition, occurs in up to $30 \%$ of all patients and anemia is nearly the second cause of ARF in the intensive care unit. ${ }^{16}$

Until recently, there has been no consensus as to diagnostic criteria or clinical definition of ARF. The RIFLE criteria were developed to standardize the diagnosis of ARF and, in the process, the term acute kidney injury (AKI) has been proposed to encompass the entire spectrum of the syndrome from minor changes in renal function to requirement for renal replacement therapy. ${ }^{14}$ Thus, AKI is not just ARF but a more general description. Indeed, small changes in kidney function in patients having cardiac surgery are important and significantly affect short- and possibly long-term outcomes. ${ }^{17}$ The RIFLE criteria provide a uniform definition of AKI and have now been validated in numerous studies in the cardiac surgery setting. ${ }^{18,19}$ Data from the present study are consistent with published series demonstrating that costs, lengths of hospital stay, and mortality are higher in patients in whom AKI develops after cardiac surgery according to RIFLE criteria, and these values increase as AKI severity worsens.

AKI pathogenesis is complex and multifactorial. It likely involves at least six major injury pathways: exogenous and endogenous toxins, metabolic factors, ischemia and reperfusion, neurohormonal activation, inflammation, and oxidative stress. These mechanisms of injury are likely to be active at different times with different intensity and probably act synergistically. ${ }^{16}$

Recently, major studies found preoperative anemia to be an independent predictor of AKI. ${ }^{3-6}$ Both studies were unable to define the specific pathogenetic pathway but stressed the role of reduced oxygen delivery and the harms of transfusions, known predictors of postoperative kidney dysfunction. ${ }^{20}$ 
TABLE 4. Outcomes

\begin{tabular}{|c|c|c|c|c|}
\hline Outcomes & Study population $(n=1047)$ & Anemia present $(\mathbf{n}=\mathbf{3 2 0})$ & Anemia absent $(n=727)$ & $P$ value \\
\hline Cardiac complications $(\%)$ & 7.3 & 10.3 & 5.9 & .014 \\
\hline Peak eGFR $\left(\mathrm{mL} \cdot \min ^{-1} \cdot\left[1.73 \mathrm{~m}^{2}\right]^{-1}\right)$ & $64.2 \pm 31.6$ & $60.2 \pm 49.56$ & $66.2 \pm 18.7$ & $<.0001$ \\
\hline CVVH $(\%)$ & 3.4 & 6.4 & 2.2 & .002 \\
\hline Prolonged ventilation $(>24 \mathrm{~h})(\%)$ & 3.2 & 5.3 & 2.3 & .021 \\
\hline Stroke $(\%)$ & 1.9 & 2.8 & 1.5 & .22 \\
\hline Deep sternal wound infection $(\%)$ & 1.5 & 1.5 & 1.6 & 1.0 \\
\hline ICU stay $(d)$ & $3.2 \pm 3.9$ & $3.9 \pm 5.2$ & $2.9 \pm 3.2$ & $<.0001$ \\
\hline Hospital stay $(\mathrm{d})$ & $8.07 \pm 4.7$ & $8.9 \pm 5.8$ & $7.6 \pm 4.1$ & $<.0001$ \\
\hline Hospital death $(\%)$ & 3.9 & 7.8 & 2.2 & $<.0001$ \\
\hline
\end{tabular}

$e G F R$, Estimated glomerular filtration rate; $C V V H$, continuous venovenous hemofiltration; $I C U$, intensive care unit.

Pathogenesis of target events is well beyond the aims and possibilities of the present series; nevertheless, it is important to notice that anemic patients had a significantly lower oxygen delivery along with lower nadir hematocrit value on $\mathrm{CPB}$, and they had lower hemoglobin levels throughout the entire process of care combined with significantly higher cardiac morbidity and transfusions requirements. In this respect, it is noteworthy that the propensity score for the likelihood to receive transfusion appeared as another independent predictor of AKI. First, it powerfully reinforces the role of preoperative anemia. Second, such findings closely mirror results of large authoritative reports on drawbacks of red blood cell transfusion on cardiac surgery outcomes. ${ }^{20}$

As to secondary end points, the lack of a dose-response relationship between preoperative anemia and AKI, in the context of at most moderate severity, further enhances the importance of this feature, arguing in favor of a low threshold attention toward the problem of preoperative any-degree anemia in patients scheduled for CABG. Although the markedly skewed distribution of patients within the three groups of different anemia WHO grades may have negatively affected the statistical power of the analysis of dose-response relationship between anemia and AKI, such patient popula-

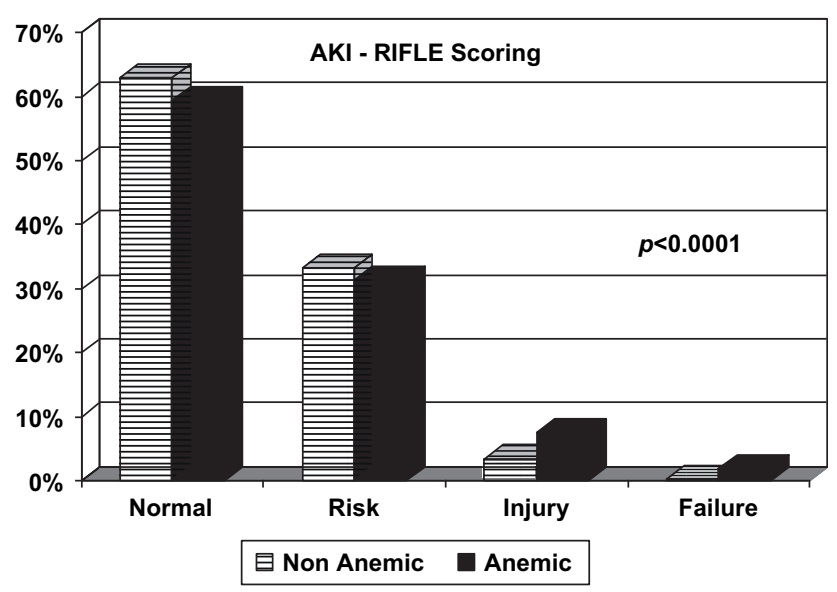

FIGURE 1. RIFLE scoring in the anemic and nonanemic subsets. AKI, Acute kidney injury; RIFLE, Risk, Injury, Failure, Loss, End-stage kidney disease. tion composition reflects the "real-world" scenario and is similar to those reported in previous studies. ${ }^{3-6}$

Final considerations deserve the results of multivariable analysis for cardiac morbidity predictors. Beside known determinants (recent myocardial infarction and CPB time), transfusions statistically emerged. This finding is homogeneous with data forwarded by Surgenor and coworkers. ${ }^{21}$ In that study, exposure to both hemodilutional anemia and red blood cell transfusion during surgery were indeed associated with increased risk of low-output heart failure after CABG.

\section{Study Overview}

Several study limitations should be considered for a thorough data interpretation. First, the single-center setting, although guaranteeing a uniform process of care with special emphasis on transfusion triggers, closely reflects the influence of specific standards of clinical practice and a unique patient population that may have led to one-sided results not readily transferable to other patient populations. On the other side, correctness of statistical tools in balancing for confounders makes results of this analysis, of an

TABLE 5. Independent risk factors for primary end points

\begin{tabular}{|c|c|c|c|c|}
\hline $\begin{array}{l}\text { Primary end points } \\
\text { and risk factors }\end{array}$ & $\beta$ & OR & $95 \%$ CI & $P$ value \\
\hline \multicolumn{5}{|l|}{ Hospital mortality } \\
\hline Age & 0.056 & 1.06 & $1.002-1.116$ & .041 \\
\hline Baseline eGFR & 0.024 & 0.98 & $0.96-0.99$ & .006 \\
\hline RIFLE & 2.53 & 12.53 & $5.29-29.7$ & $<.001$ \\
\hline Propensity score & 0.87 & 2.4 & $1.65-3.43$ & $<.001$ \\
\hline \multicolumn{5}{|l|}{ Acute kidney injury } \\
\hline Preoperative anemia & 0.72 & 2.06 & $1.14-3.70$ & .016 \\
\hline IDDM & 1.03 & 2.8 & $1.20-6.50$ & .017 \\
\hline Propensity score & 0.80 & 2.23 & $1.80-2.80$ & $<.001$ \\
\hline \multicolumn{5}{|l|}{ Cardiac morbidity } \\
\hline $\begin{array}{l}\text { Recent myocardial } \\
\text { infarction }\end{array}$ & 0.7 & 2.07 & $1.02-4.20$ & .043 \\
\hline Transfusion & 1.15 & 3.16 & $1.73-5.80$ & $<.001$ \\
\hline Peak eGFR & -0.02 & 0.98 & $0.971-0.994$ & .002 \\
\hline $\mathrm{CPB}$ duration & 0.007 & 1.007 & $1.001-1.013$ & .026 \\
\hline
\end{tabular}

$O R$, Odds ratio; $C I$, confidence intervals; $e G F R$, estimated glomerular filtration rate RIFLE, Risk, Injury, Failure, Loss, End-stage kidney disease; IDDM, insulin-dependent diabetes mellitus; $C P B$, cardiopulmonary bypass. 
unselected consecutive series of patients experiencing almost all clinically relevant events, transferable.

Second, oxygen delivery was determined only during $\mathrm{CPB}$. The finding that hemoglobin concentrations at study time points were markedly lower in the anemic subset than in the nonanemic counterpart, in the absence of data on tissue oxygen supply, substantially prevents an unbiased definition of the mechanisms by which preoperative anemia led to increased morbidity and mortality.

Third, given the observational nature of our study, we cannot determine the causal relationship between anemia and risk of postoperative adverse events; neither can we relate the etiology and chronicity of the illness with outcomes. This is particularly important when considering the treatment of abnormal hemoglobin values. If these changes are reflective of underlying conditions, then severity of preoperative anemia may be a marker of risk and not a modifiable risk factor.

\section{CONCLUSIONS}

This single-center prospective observational study found that preoperative anemia is an independent predictor of AKI, a major determinant of hospital mortality after CABG. Further studies are warranted to determine whether preoperative low hemoglobin concentration is a marker of severity of illness or a modifiable risk factor.

\section{References}

1. Murphy GJ, Angelini GD. Indications for blood transfusion in cardiac surgery. Ann Thorac Surg. 2006;82:2323-34.

2. Gardner TJ. To transfuse or not to transfuse. Circulation. 2007;116:458-60.

3. Zindrou D, Taylor KM, Bagger JP. Preoperative haemoglobin concentration and mortality rate after coronary artery bypass surgery. Lancet. 2002;359:1747-8.

4. Cladellas M, Bruguera J, Comin J, Vila J, de Jaime E, Marti J, et al. Is preoperative anaemia a risk marker for in-hospital mortality and morbidity after valve replacement? Eur Heart J. 2006;27:1093-9.

5. Kulier A, Levin J, Moser R, Rumpold-Seitlinger G, Tudor IC, Snyder-Ramos SA, et al. Impact of preoperative anemia on outcome in patients undergoing coronary artery bypass graft surgery. Circulation. 2007;116:471-9.

6. Karkouti K, Wijeysundera DN, Beattie WS, for the Reducing Bleeding in Cardiac Surgery (RBC) Investigators. Risk associated with preoperative anemia in cardiac surgery: a multicenter cohort study. Circulation. 2008;117:478-84.
7. Onorati F, De Feo M, Mastroroberto P, Cristodoro L, Pezzo F, Renzulli A, et al. Determinants and prognosis of myocardial damage after coronary artery bypass grafting. Ann Thorac Surg. 2005;79:837-45.

8. De Santo LS, Bancone C, Santarpino G, Romano G, De Feo M, Scardone M, et al. Microbiologically documented nosocomial infections after cardiac surgery: an 18-month prospective tertiary care centre report. Eur J Cardiothorac Surg. 2008;33:666-72.

9. Society of Thoracic Surgeons Blood Conservation Guideline Task Force, Ferraris VA, Ferraris SP, Saha EA 2nd, Haan CK, Royston BD, et al: Society of Cardiovascular Anesthesiologists Special Task Force on Blood Transfusion, Spiess BD, Shore-Lesserson L, Stafford-Smith M, Mazer CD, Bennett-Guerrero E, Hill SE, et al. Perioperative blood transfusion and blood conservation in cardiac surgery: the Society of Thoracic Surgeons and The Society of Cardiovascular Anesthesiologists clinical practice guideline. Ann Thorac Surg. 2007;83:S27-86.

10. Ranucci R, Romitti F, Isgrò $\mathrm{G}$, Cotza $\mathrm{M}$, Brozzi S, Boncilli $\mathrm{A}$, et al. Oxygen delivery during cardiopulmonary bypass and acute renal failure after coronary operations. Ann Thorac Surg. 2005;80:2213-20.

11. World Health Organization. Iron deficiency anaemia: assessment, prevention, and control: 2001. Available at:http://whqlibdoc.who.int/hq/2001/WHO_NHD_01.3.pdf.

12. Levey AS, Bosch JP, Lewis JB, Greene T, Rodgers N, Roth D. A more accurate method to estimate glomerular filtration rate from serum creatinine: a new prediction equation. Ann Intern Med. 1999;130:461-70.

13. National Kidney Foundation. K/DOQI clinical practice guidelines for chronic kidney disease: evaluation, classification, and stratification. Am J Kidney Dis. 2002;39:S1-266.

14. Bellomo R, Ronco C, Kellum JA, Mehta RL, Palevsky P. Acute Dialysis Quality Initiative workgroup: acute renal failure-definition, outcome measures, animal models, fluid therapy and information technology needs: the Second International Consensus Conference of the Acute Dialysis Quality Initiative (ADQI) Group. Crit Care. 2004;8:R204-12.

15. D'Agostino RB. Propensity score methods for bias reduction in the comparison of a treatment to a non-randomized control group. Stat Med. 1998;17:2265-81.

16. Bellomo R, Auriemma S, Fabbri A, D'Onofrio A, Katz N, McCullough PA, et al. The pathophysiology of cardiac surgery-associated acute kidney injury (CSAAKI). Int J Artif Organs. 2008;31:166-78.

17. Lassnigg A, Schmid ER, Hiesmayr M, Falk C, Druml W, Bauer P, et al. Impact of minimal increases in serum creatinine on outcome in patients after cardiothoracic surgery: do we have to revise current definitions of acute renal failure? Crit Care Med. 2008;36:1129-37.

18. Dasta JF, Kane-Gill SL, Durtschi AJ, Pathak DS, Kellum JA. Costs and outcomes of acute kidney injury (AKI) following cardiac surgery. Nephrol Dial Transplant. 2008;23:1970-4.

19. Kuitunen A, Vento A, Suojaranta-Ylinen R, Pettilä V. Acute renal failure after cardiac surgery: evaluation of the RIFLE classification. Ann Thorac Surg. 2006;81:542-6.

20. Murphy GJ, Reeves BC, Rogers CA, Rizvi SI, Culliford L, Angelini GD. Increased mortality, postoperative morbidity, and cost after red blood cell transfusion in patients having cardiac surgery. Circulation. 2007;116:2544-52.

21. Surgenor SD, DeFoe GR, Fillinger MP, Likosky DS, Groom RC, Clark C, et al. Intraoperative red blood cell transfusion during coronary artery bypass graft surgery increases the risk of postoperative low-output heart failure. Circulation. 2006;114:I43-8 